\title{
Consequences of Internet Addiction on Dietary Behavior among Adolescents in Assiut City
}

Fatma A. Mekhemer ${ }^{1}$, Eman Sayed Ahmed ${ }^{2}$ \& Atyat Mohammed Hassan ${ }^{3}$.

1. Nursing Specialist at Dermoas Hospital, El-Minia, Egypt.

2. Professor of Pediatric and Premature Nursing, Faculty of Nursing, Assiut University, Egypt.

3. Lecturer of Pediatric and Premature Nursing, Faculty of Nursing, Assiut University, Egypt.

\begin{abstract}
Background: Internet addiction has an unfavorable impact on dietary habits of adolescents. The aim was to assess the consequences of internet addiction on dietary behavior of adolescents in Assiut city. Design: Correlational descriptive research design was used in this study. Setting: Four governmental secondary schools in Assiut city were the setting of the study. Subjects: A representative sample of 400 adolescents was recruited for this study. A stratified sampling technique was used. Tools: Three tools were utilized to collect the data: Socioeconomic scale, internet addiction test, and dietary behavior and diet quality questionnaire. Results: More than one-third of the studied adolescents had occasional to frequent problem due to internet use and near to one-quarter of them had a significant problem from internet use. Also, they were skipping meals, snacking frequently, had a poorer appetite, and bad diet quality. Conclusion: Adolescent students who had significant problem from internet use had improper dietary behavior, a poorer diet quality than their counterparts who had control over internet use. Recommendations: Raising adolescents' awareness through mass media and health education program in schools and family-centered care about adverse effects of internet addiction on their development especially dietary behavior.
\end{abstract}

\section{Keywords: Adolescents, Consequences, Internet Addiction \& Dietary Behavior.}

\section{Introduction}

Adolescence is a period of numerous changes for young adults for example there is a rapid rate of physical growth. Adolescents are influenced by outside factors such as; parents, peers, culture, religion, school, community, world events and modern technology (Eccles, 2011) One of the greatest influential types of modern technology which has big effect on daily life of adolescents is the internet. In recent years the internet has assumed an important place in our lives. The internet has become more accessible in homes, schools, colleges, libraries and internet cafes (United Nations, 2011).

According to Internet world status; Egypt Internet Usage \& Tele-communications Report, (2012) the total number of worldwide internet users was estimated as 29 million users in 2012, increased to about $54.6 \%$ of the population in 2015 (Statistics of Internet Users Worldwide in Millions, 2015). While reaching to 34.800 million users in 2017 in Egypt (Internet Users Statistics for Africa, 2017) and jumped to be 49.231 million users in 2018 in Egypt (Internet Users Statistics for Africa in millions, 2018).

Internet usage is highly prevalent among adolescent children (Malak et al., 2017 \& Kawabe et al., 2016). It is reported that the age group that most frequently uses the internet is 14-24 years (Odac \& Kalkan, 2010) Also, a study by Kim et al., (2010) declared that adolescents are the frequently exposed people for Internet Addiction (IA). As they prefer to communicate with others on social networking sites rather than the actual contact in the real world. Internet Addiction is "defined as overuse of the internet leading to impairment of an individual's psychological state (both mental and emotional), as well as their occupational and social interactions (Vondrácková \& Gabrhelík, 2016).

There are many social, cultural, and psychological factors associated with eating attitudes and behaviors. In developing countries, diet, cultural and social changes, westernization, family atmosphere, contact to mass media, technology, internet use, and globalization, all of these factors have a major effect on eating attitudes and dietary behaviors, specifically between adolescents (Musaiger et al., 2013) It was found that adolescents spend a long time on the internet and this can cause irregular eating habits, skipping meals, eating an unbalanced diet and affect other similar activities of daily life (Gur et al., 2015). Children should be educated as to what a balanced diet and optimum physical activity routine is to remain healthy and grow. Moreover, the government should precede an active role in planning and appraising IA-related health intervention plans. Given the likely adverse effects of internet addiction on adolescents' development because of poor dietary behavior, it is critical for the pediatric nurse to raise awareness about IA. Close attention should be given to adolescents at risk of IA, as well as adolescents at

Vol , (7) No , (17) June, 2019 
low risk to inhibit them from becoming addicted to the internet (Kim et al., 2010).

\section{Significance of the study}

High-risk internet users have improper nutritional manners and poor diet quality which could result in stunted growth and development of adolescents (Kim et al., 2010). Nevertheless, knowledge of the impact of IA on the dietary behavior of adolescents is limited. So, in this study; we will examine the relationship between IA and its effect dietary behavior of adolescents.

\section{Aim of the study}

This study aimed to assess the consequences of internet addiction on dietary behavior among adolescents in Assiut city.

\section{Research question}

- What are the consequences of internet addiction on dietary behavior among adolescents in Assiut city?

\section{Materials \& Method \\ Study design}

- Correlational descriptive research design was used in this study.

\section{Study Setting}

This study was carried out at four general governmental secondary schools in Assiut City. The selected schools represented all directions in Assiut City. These include; El- Gamaa Al Mowhada Secondary School (for girls), Fossol El-Walidya Secondary School (for girls), Gamal Farghaly Sultan Secondary School (for boys), and Nasser El-Askarya Secondary School (for boys).

\section{Study Subjects}

A representative sample of adolescents was recruited in this study. A list of all governmental secondary schools was obtained from the directorate of education in Assiut City. One school was selected randomly from each direction (North, South, East, and West) in Assiut City. The researcher followed a stratified random sampling technique inside each school. Two classes for each grade (first and second) were chosen randomly from each school. The number of students in each class ranged from (20-30) students. The researcher interviewed all children to fill the sheet in the selected classes. The total sample was 400 adolescents. Adolescents' consents for participation were gotten in this study with the following inclusion criteria:

1. Middle adolescent aged from 15-17 years old.

\section{Sample size}

Study subjects' number was detected according to the total number of students in all public secondary schools in Assiut city, which was 4995 by using sample size estimation according to EPi info version
3 with precision levels $5 \%$ where confidence level is $95 \%$ and $\mathrm{p} \leq 0.05$. The actual sample size was 357 students. It was increased to 450 to compensate any drop out. Approximately, 50 students were excluded because of either incomplete data or they didn't want to participate in the study.

Study Tools:

Three tools were utilized to collect the data after reviewing the relevant literatures:

\section{Tool (I): Socioeconomic scale: It included two} parts

- Part (1) Personal characteristic: It included: students' age, gender and school class

- Part (2): It was adapted from Abd El Tawab, (1998) and used to assess socioeconomic status. It included family income per month (6 sub items) and educational level of the parent ( 7 sub items), parent occupation and family's life style (3 sub items). One score has given for each item. The total score was categorized into three social classes as; high from $85-100 \%$, moderate from $60-84 \%$, and low was less than $60 \%$. The item of income was modified according to the rate of inflation and increased to be confirming with recent income through comparing the difference of the value of golden pound in 1998 to that in 2018 and multiplying the rate of inflation to the scale as the following: The golden pound's value in 1998 was 185 Egyptian pounds, while the value of golden pound in 2018 was 5216 Egyptian pounds. The rate of inflation $=5216 / 185$, the rate of inflation was 28.19 times.

Tool (I): Internet Addiction Test (IAT):

It was adopted from Young (2004): This is a 20-item inventory parent-child internet addiction test.

This scale consists of four domains as the following:

1. The first domain is interference with family relationships (6 items) such as do you prefer to spend time online rather than with the rest of your family?

2. The second is salience and withdrawal (8 items) (such as do you withdraw from others since discovering the Internet?)

3. The third domain is overindulgence in online relationships (4 items) (such as do you spend time alone in your room playing on the computer?)

4. The fourth is tolerance and neglecting daily routines ( 2 items) (such as do you neglect daily routines, such as bathing and eating, to spend more time online?)

The adolescents were invited to rate the items on a five-point Likert scale extending from (1 to 5). For every response: rarely $=1$, sometimes $=2$, frequently $=3$, often $=4$ and always $=5$. The minimum score was 20 , while the maximum was 
100; the higher the score the greater the problems of internet use. A score of 20-49 was an average online user who has control of usage, a score of 50-79 indicated occasional to frequent problems due to internet use, and a score of 80-100 indicated that the internet is causing significant problems. The results of previous studies by Young (1998a, 1998b, 2004) indicated that the IAT had adequate construct validity. Also, all of the IAT domains showed good to moderate internal consistency (alpha coefficients ranged from 0.63 to 0.82 ).

Tool (II): Dietary behavior and diet quality questionnaire: It was developed by Kim et al. (2003) and composed of 3 parts:

- Part (1): Change in dietary habits include $3 \mathrm{sub}$ items:-

Changes in meal size, changes in appetite and changes in eating speed

- Part (2): Snaking pattern include 7 sub items:Skipping breakfast, skipping lunch, skipping dinner, reasons for meal skipping, frequency of snacking, snack items, reasons for snacking.

- Part (3): Diet quality was assessed by using $10 \mathrm{sub}$ items mini dietary assessment index used to assess overall dietary quality. This index includes four food groups that should be consumed, four food groups of which limited amounts should be consumed, and two items regarding varied and regular diet. Responses to food items of which sufficient amounts should be consumed were reported using a 3-point Likert scale where $1=$ seldom, 3=sometimes, and 5=always. Responses to food items of which limited quantities should be consumed were also reported using a 3-point Likert scale where 1=always, 3=sometimes, and $5=$ seldom. The maximum possible score for diet quality was 50. In this study, diet quality was defined as "good" if the total score was greater than or equal to 30 while diet quality was defined as "bad" if the total score was less than 30.

\section{Procedure}

An official permission to collect the data was obtained from Ministry of Education in Assiut governorate. The tools were prepared, translated into Arabic language and reviewed by five experts in the field of pediatric nursing to ascertain their content validity index, it was 0.97 . Internal consistency of the Arabic version of the tools was done using alpha Cronbach test. Alpha coefficients were 0.94 for internet addiction test and ranging from 0.68 to 0.81 for quality of diet. This indicated good reliability.

\section{Ethical considerations}

The study proposal was accepted by the Ethical Committee of Faculty of Nursing. The adolescent students were informed about the study and they were advised that they were under no obligation to participate in the study and the study will not affect their education or assessment. Confidentiality and anonymity were assured. Adolescents had the rights to refuse to participate in the study without any rational.

\section{A pilot study}

The pilot study was carried out on 40 (10\%) adolescents. It was accomplished to estimate the feasibility and clarity of the study tools and the desirable time to accomplish the questionnaire. It was excluded from the total sample. As the results of the pilot study, the necessary modifications were done (two items as "adding salts and soya sauce" to adding "salts and katshab" and " eating stir-fried food " to " eat fried food to match with our community tradition). The time needed to fill out the sheet was 15-20 minutes

\section{Field of the work}

Data were collected during the period from the beginning of January 2018 to the end of May 2018 (5 months). Data collection was done by the researcher during the school day. The data were collected according to every school day. The actual work started by meeting the school manager in the morning. Firstly, the researcher introduced herself to and gave them a complete background about the study and the sheet format which was predesigned by the researcher in Arabic language in order to collect the required data. Then the researcher went to students' classroom during activity lesson and introduced herself, also, explained the research aim. After that the questionnaire was distributed. The researcher invited the students to participate in the study by filling out questionnaire.

Students were asked to read each question carefully and to answer the questions honestly. Students were asked to circle the answer that best describe them. The researcher was available for more clarification whenever needed. Students' participation was voluntary and once the student completed the questionnaires the researcher collected the questionnaires from the students by herself in every visit. The time needed was about $45-60$ minutes for each class. The researcher visited each school from three to four times per week to collect data.

\section{Statistical Analysis}

The data were analyzed for normality by the Anderson-Darling test and for homogeneity variances before starting the statistical analysis. The number and percent were used in categorical variables which were compared by Chi-square test and Fisher exact test. While Mean and SD were used in continuous variables which were compared by Oneway ANOVA test and a t-test. Also, the statistical significant differences were found at $=\mathrm{P}<0.05$. 
The correlation between variables was found by using the Pearson and Spearman correlation. The statistical analysis was done by using IBM SPSS 20.0 software.

\section{Results}

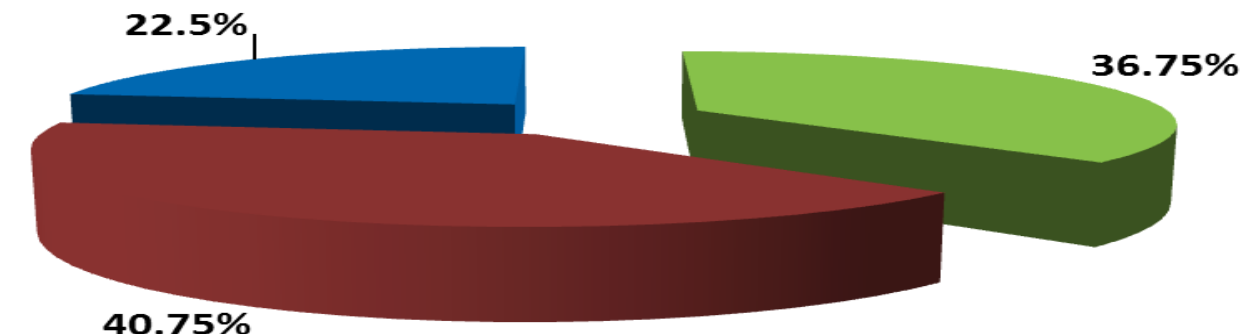

Control overinternet Occasional to frequent problem $\square$ Significant problem

Figure (1): Levels of internet addiction of the studied adolescents $(n=400)$.

Table (1): Relationship between levels of internet addiction test and biosocial data of studied adolescents $(\mathbf{n}=\mathbf{4 0 0})$.

\begin{tabular}{|c|c|c|c|c|c|c|c|c|c|}
\hline \multirow{3}{*}{ Biosocial data } & \multirow{3}{*}{$\begin{array}{c}\% \\
(n=400)\end{array}$} & \multicolumn{6}{|c|}{ Levels of internet addiction } & \multirow{3}{*}{$\mathbf{X}^{2}$} & \multirow{3}{*}{ P.value } \\
\hline & & \multicolumn{2}{|c|}{$\begin{array}{c}\text { Control over } \\
\text { internet }\end{array}$} & \multicolumn{2}{|c|}{$\begin{array}{l}\text { Frequent } \\
\text { problem }\end{array}$} & \multicolumn{2}{|c|}{$\begin{array}{c}\text { Significant } \\
\text { problem }\end{array}$} & & \\
\hline & & No & $\%$ & No & $\%$ & No & $\%$ & & \\
\hline \multicolumn{10}{|l|}{ Age(years): } \\
\hline $15-$ & 16.5 & 21 & 14.3 & 30 & 18.4 & 15 & 16.7 & \multirow{4}{*}{5.178} & \multirow{4}{*}{0.521} \\
\hline 16- & 39.5 & 57 & 38.8 & 65 & 39.9 & 36 & 40.0 & & \\
\hline 17 & 44 & 69 & 46.9 & 68 & 41.7 & 39 & 43.3 & & \\
\hline Total & 100 & 147 & 100 & 163 & 100 & 90 & 100 & & \\
\hline \multicolumn{10}{|l|}{ Sex : } \\
\hline - $\quad$ Male & 50 & 60 & 40.8 & 79 & 48.5 & 61 & 67.8 & \multirow{3}{*}{16.49} & \multirow{3}{*}{$<0.001 * *$} \\
\hline - $\quad$ Female & 50 & 87 & 59.2 & 84 & 51.5 & 29 & 32.2 & & \\
\hline Total & 100 & 147 & 100 & 163 & 100 & 90 & 100 & & \\
\hline \multicolumn{10}{|l|}{ School grade: } \\
\hline - $\quad$ First grade & 50 & 68 & 46.3 & 84 & 51.5 & 48 & 53.3 & \multirow{3}{*}{1.377} & \multirow{3}{*}{0.502} \\
\hline $\begin{array}{ll}\text { - } & \text { Second } \\
\text { grade }\end{array}$ & 50 & 79 & 53.7 & 79 & 48.5 & 42 & 46.7 & & \\
\hline Total & 100 & 147 & 100 & 163 & 100 & 90 & 100 & & \\
\hline
\end{tabular}

Table (2): Relationship between internet addiction test and changes in dietary habits of the studied adolescents $(n=400)$.

\begin{tabular}{|c|c|c|c|c|c|c|c|c|}
\hline \multirow{3}{*}{ Dietary habits } & \multicolumn{6}{|c|}{ Internet addiction levels } & \multirow{3}{*}{$X^{2}$} & \multirow{3}{*}{ P. value } \\
\hline & \multicolumn{2}{|c|}{$\begin{array}{c}\text { Control over } \\
\text { internet }\end{array}$} & \multicolumn{2}{|c|}{$\begin{array}{c}\text { Frequent } \\
\text { problem }\end{array}$} & \multicolumn{2}{|c|}{$\begin{array}{c}\text { Significant } \\
\text { problem }\end{array}$} & & \\
\hline & No & $\%$ & No & $\%$ & No & $\%$ & & \\
\hline \multicolumn{9}{|l|}{ Changes in meal size: } \\
\hline - Increased & 23 & 15.6 & 78 & 47.9 & 70 & 77.8 & \multirow{3}{*}{125.15} & \multirow{3}{*}{$<0.001 * *$} \\
\hline - Decreased & 15 & 10.2 & 32 & 19.6 & 15 & 16.7 & & \\
\hline - $\quad$ No change & 109 & 74.1 & 53 & 32.5 & 5 & 5.6 & & \\
\hline
\end{tabular}




\begin{tabular}{|c|c|c|c|c|c|c|c|c|}
\hline \multirow{3}{*}{ Dietary habits } & \multicolumn{6}{|c|}{ Internet addiction levels } & \multirow{3}{*}{$\mathbf{X}^{2}$} & \multirow{3}{*}{ P. value } \\
\hline & \multicolumn{2}{|c|}{$\begin{array}{c}\text { Control over } \\
\text { internet }\end{array}$} & \multicolumn{2}{|c|}{$\begin{array}{c}\text { Frequent } \\
\text { problem }\end{array}$} & \multicolumn{2}{|c|}{$\begin{array}{c}\text { Significant } \\
\text { problem }\end{array}$} & & \\
\hline & No & $\%$ & No & $\%$ & No & $\%$ & & \\
\hline \multicolumn{9}{|l|}{ Changes in appetite } \\
\hline - Better & 25 & 17.0 & 8 & 4.9 & 0 & 0.0 & \multirow{4}{*}{200.02} & \multirow{4}{*}{$<0.001 * *$} \\
\hline - Worse & 6 & 4.1 & 105 & 64.4 & 75 & 83.3 & & \\
\hline - $\quad$ No change & 86 & 58.5 & 19 & 11.7 & 7 & 7.8 & & \\
\hline - Do not know & 30 & 20.4 & 31 & 19.0 & 8 & 8.9 & & \\
\hline \multicolumn{9}{|c|}{ Changes in eating speed: } \\
\hline • Fast & 9 & 6.1 & 25 & 15.3 & 46 & 51.1 & \multirow{4}{*}{246.59} & \multirow{4}{*}{$<0.001 * *$} \\
\hline - $\quad$ Slow & 15 & 10.2 & 17 & 10.4 & 4 & 4.4 & & \\
\hline - $\quad$ Average & 107 & 72.8 & 18 & 11.0 & 0 & 0.0 & & \\
\hline - Irregular & 16 & 10.9 & 103 & 63.2 & 40 & 44.4 & & \\
\hline
\end{tabular}

Table (3): Relationship between internet addiction test and skipping meal of the studied adolescents (n=400).

\begin{tabular}{|c|c|c|c|c|c|c|c|c|}
\hline \multirow{3}{*}{ Skipping meal } & \multicolumn{6}{|c|}{ Internet addiction levels } & \multirow{3}{*}{$\mathbf{X}^{2}$} & \multirow{3}{*}{ P. value } \\
\hline & \multicolumn{2}{|c|}{$\begin{array}{c}\text { Control over } \\
\text { internet }\end{array}$} & \multicolumn{2}{|c|}{$\begin{array}{c}\text { Frequent } \\
\text { problem }\end{array}$} & \multicolumn{2}{|c|}{$\begin{array}{c}\text { Significant } \\
\text { problem }\end{array}$} & & \\
\hline & No & $\%$ & No & $\%$ & No & $\%$ & & \\
\hline \multicolumn{9}{|l|}{ Skipping breakfast: } \\
\hline$\bullet \quad \mathrm{No}$ & 110 & 74.8 & 30 & 18.4 & 11 & 12.2 & \multirow{2}{*}{136.92} & \multirow{2}{*}{$<0.001 * *$} \\
\hline - $\quad$ Yes & 37 & 25.2 & 133 & 81.6 & 79 & 87.8 & & \\
\hline \multicolumn{9}{|l|}{ Skipping Lunch: } \\
\hline$\bullet \quad \mathrm{No}$ & 138 & 93.9 & 134 & 82.2 & 59 & 65.6 & \multirow{2}{*}{31.42} & \multirow{2}{*}{$<0.001 * *$} \\
\hline - $\quad$ Yes & 9 & 6.1 & 29 & 17.8 & 31 & 34.4 & & \\
\hline \multicolumn{9}{|l|}{ Skipping Dinner: } \\
\hline$\bullet \quad \mathrm{No}$ & 120 & 81.6 & 50 & 30.7 & 29 & 32.2 & \multirow{2}{*}{94.55} & \multirow{2}{*}{$<0.001 * *$} \\
\hline - $\quad$ Yes & 27 & 18.4 & 113 & 69.3 & 61 & 67.8 & & \\
\hline \multicolumn{9}{|l|}{ Reasons for meal skipping: } \\
\hline$\bullet \quad$ Over sleep & 11 & 7.5 & 35 & 21.5 & 39 & 43.3 & \multirow{7}{*}{172.44} & \multirow{7}{*}{$<0.001 * *$} \\
\hline - $\quad$ No appetite & 15 & 10.2 & 29 & 17.8 & 4 & 4.4 & & \\
\hline $\begin{array}{l}\text { - Snacking before a } \\
\text { meal }\end{array}$ & 12 & 8.2 & 62 & 38.1 & 33 & 36.7 & & \\
\hline - $\quad$ Weight loss & 14 & 9.5 & 2 & 1.2 & 0 & 0.0 & & \\
\hline - $\quad$ Saving money & 4 & 2.7 & 0 & 0.0 & 0 & 0.0 & & \\
\hline - $\quad$ Lack of time & 20 & 13.6 & 13 & 8.0 & 12 & 13.3 & & \\
\hline - $\quad$ Habit & 71 & 48.3 & 22 & 13.5 & 2 & 2.2 & & \\
\hline
\end{tabular}


Table (4): Relationship between internet addiction test and snaking pattern of the studied adolescents $(\mathrm{n}=\mathbf{4 0 0})$.

\begin{tabular}{|c|c|c|c|c|c|c|c|c|}
\hline \multirow{3}{*}{ Snaking pattern } & \multicolumn{6}{|c|}{ Internet addiction levels } & \multirow{3}{*}{$\mathbf{X}^{2}$} & \multirow{3}{*}{ P. value } \\
\hline & \multicolumn{2}{|c|}{$\begin{array}{c}\text { Control } \\
\text { over } \\
\text { internet }\end{array}$} & \multicolumn{2}{|c|}{$\begin{array}{l}\text { Frequent } \\
\text { problem }\end{array}$} & \multicolumn{2}{|c|}{$\begin{array}{c}\text { Significant } \\
\text { problem }\end{array}$} & & \\
\hline & No & $\%$ & No & $\%$ & No & $\%$ & & \\
\hline \multicolumn{9}{|l|}{ Frequency of snacking: } \\
\hline - 3 times or more per day & 14 & 9.5 & 49 & 30.1 & 60 & 66.7 & \multirow{3}{*}{181.77} & \multirow{3}{*}{$<0.001 * *$} \\
\hline - 1-2 times per day & 71 & 48.3 & 114 & 69.9 & 30 & 33.3 & & \\
\hline - None & 62 & 42.2 & 0 & 0.0 & 0 & 0.0 & & \\
\hline \multicolumn{9}{|l|}{ Snack items: } \\
\hline - $\quad$ Confectionery & 15 & 10.2 & 21 & 12.9 & 11 & 12.2 & \multirow{6}{*}{223.82} & \multirow{6}{*}{$<0.001 * *$} \\
\hline - $\quad$ Soda & 16 & 10.9 & 43 & 26.4 & 7 & 7.8 & & \\
\hline - $\quad$ Fried food & 16 & 10.9 & 50 & 30.7 & 14 & 15.6 & & \\
\hline - $\quad$ Fruits & 72 & 49.0 & 13 & 8.0 & 0 & 0.0 & & \\
\hline - $\quad$ Milk & 16 & 10.9 & 0 & 0.0 & 0 & 0.0 & & \\
\hline - $\quad$ Fast food & 12 & 8.2 & 36 & 22.1 & 58 & 64.4 & & \\
\hline \multicolumn{9}{|l|}{ Reasons for snacking: } \\
\hline - Hunger & 21 & 14.3 & 58 & 35.6 & 14 & 15.6 & \multirow{5}{*}{152.41} & \multirow{5}{*}{$<0.001 * *$} \\
\hline - Lack of time for a meal & 82 & 55.7 & 48 & 29.4 & 6 & 6.7 & & \\
\hline - Habit & 14 & 9.5 & 30 & 18.4 & 64 & 71.1 & & \\
\hline - Boredom & 24 & 16.3 & 22 & 13.5 & 4 & 4.4 & & \\
\hline - Social event & 6 & 4.1 & 5 & 3.1 & 2 & 2.2 & & \\
\hline
\end{tabular}

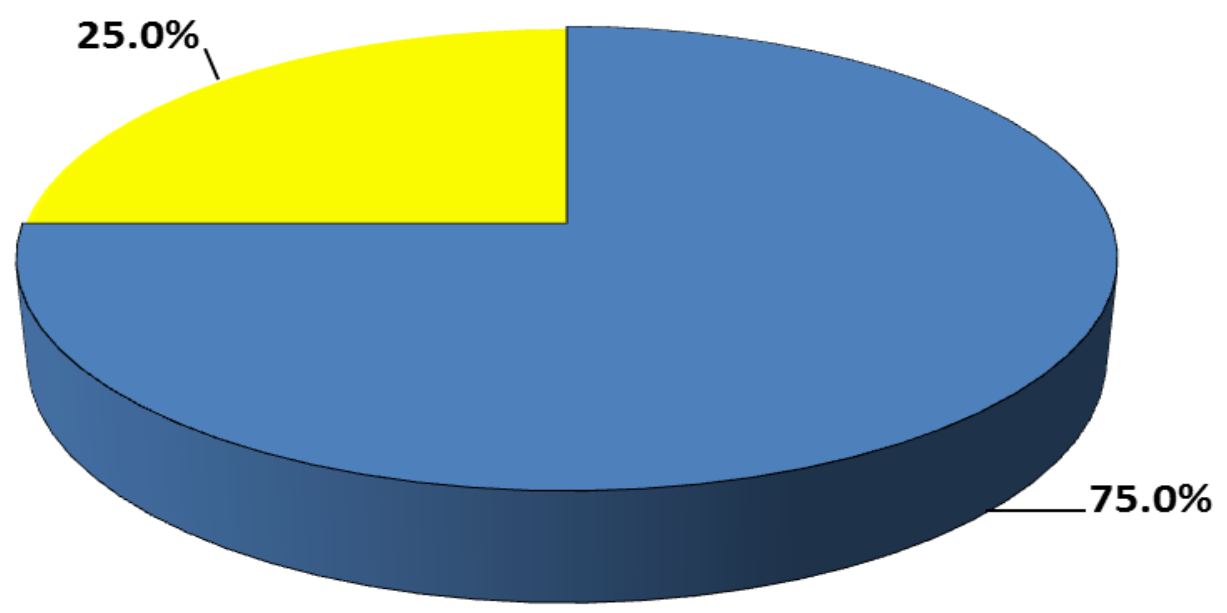

Bad Quality $\square$ Good Quality

Figure (2): levels of diet quality of the studied adolescents $(n=400)$ 
Table (5): Relationship between internet addiction test and diet quality of the studied adolescents ( $n=400)$ :

\begin{tabular}{|l|c|c|c|c|c|c|}
\hline \multirow{2}{*}{ Diet quality } & \multicolumn{5}{|c|}{ Internet addiction levels } & \multirow{2}{*}{ P.value } \\
\cline { 2 - 7 } & (Min- Max) & $\begin{array}{c}\text { Control } \\
\text { over } \\
\text { internet }\end{array}$ & $\begin{array}{c}\text { Occasional to } \\
\text { Frequent } \\
\text { problem }\end{array}$ & $\begin{array}{c}\text { Significant } \\
\text { problem }\end{array}$ & F & \\
\hline \hline $\begin{array}{l}\text { Four food } \\
\text { groups that } \\
\text { should be } \\
\text { always } \\
\text { consumed }\end{array}$ & $(4-20)$ & $13.12 \pm 2.41$ & $9.09 \pm 3.71$ & $8.84 \pm 1.59$ & 94.58 & $<0.001^{* *}$ \\
\hline $\begin{array}{l}\text { Varied and } \\
\text { regular diet }\end{array}$ & $(2-10)$ & $6.8 \pm 1.3$ & $4.81 \pm 1.67$ & $3.47 \pm 1.66$ & 141.22 & $<0.001^{* * *}$ \\
\hline $\begin{array}{l}\text { Four food } \\
\text { groups that } \\
\text { should be } \\
\text { consumed in } \\
\text { limited } \\
\text { amounts }\end{array}$ & $(4-20)$ & $7.37 \pm 2.58$ & $14.27 \pm 2.87$ & $17.16 \pm 1.41$ & 505.24 & $<0.001^{* *}$ \\
\hline \multicolumn{1}{|c|}{ Total } & $\mathbf{( 1 0 - 5 0 )}$ & $\mathbf{2 7 . 2 9 \pm 3 . 9 2}$ & $\mathbf{2 8 . 1 7 \pm 5 . 0 9}$ & $\mathbf{2 9 . 4 7 \pm 2 . 0 5}$ & $\mathbf{4 . 4 3}$ & $\mathbf{0 . 0 0 1 * *}$ \\
\hline
\end{tabular}

Table (1): Illustrates the relationship between internet addiction test and biosocial data of studied adolescents. It was clear that males were significantly more likely to have a significant problem due to internet use than females $(67.8 \%$ vs. $32.2 \%$ ) and the females were having control over internet usage than boys $(59.2 \%$ vs. $40.8 \%)$. The difference was statistically significant $(\mathrm{p}<0.001 * *)$. Also, there was no statistically significant difference between level of internet addiction and adolescents' age $(\mathrm{p}=0.521)$ and their school class $(\mathrm{p}=0.502)$.

Levels of internet addiction of the studied adolescents are illustrated in Figure (1): It was clear that more than one-third of studied adolescents (36.8\%) had control over internet use, while $40.8 \%$ of students had occasional to frequent problem due to internet use. The studied adolescents who were more likely to have significant problem from internet use were $22.5 \%$.

Table (2): Indicates the relationship between levels of internet addiction and change in dietary habits of the studied adolescents. More of studied adolescents (77.8\%) who had significant problem due to internet use their dietary habits had been changed to have big meal sizes and $83.3 \%$ of them had a worse appetite than adolescents who had control over internet use and occasional to frequent problem due to internet usage.

Regarding the changes in eating speed, $51.1 \%$ of adolescents who had significant problem due to internet use, had fast eating speed. While $44.4 \%$ of them had irregular eating speed in addition to $63.2 \%$ of adolescents who were having occasional to frequent problem due to internet usage also answered that their eating speed was irregular. This is compared to students who had control over internet use; only $6.1 \%$ had fast eating speed and 10.9 had irregular eating speed.

It was revealed from the table that there is statistical significant difference between levels of internet addiction test and change in dietary habits of the studied adolescents $(\mathrm{p}<0.001 * *)$.

Relationship between internet addiction test and skipping meal of the studied adolescents are provided in Table (3): It was shown from the table that adolescents who were having significant problem due to internet use had a high prevalence of skipping meal $(87.8 \%$ skipped breakfast and $67.8 \%$ skipped dinner). Also, adolescents who were having occasional to frequent problem due to internet usage were $81.6 \%$ skipped breakfast and $69.3 \%$ skipped dinner.

Regarding reasons for meal skipping, $43.3 \%$ of adolescents who had significant problem due to internet use answered that reasons for meal skipping was over sleep. While snacking before a meal was a reason in $36.7 \%$ of them. In contrast to studied adolescents who had control over internet use only $7.5 \%$ answered over sleep and $8.2 \%$ answered snacking before a meal.

Relationship between internet addiction test and snaking pattern of the studied adolescents are presented in table (4). Adolescents who had significant problem due to internet use snacked frequently, often snacking more than three times per day $(66.7 \%$ vs. $9.5 \%$ for studied adolescents who had control over internet use) while $69.9 \%$ of adolescents who had occasional to frequent problem due to internet usage snacked 1-2 times per day. 
It was found from the table that fast food was the favorite snack of $64.4 \%$ of adolescents who had significant problem due to internet use versus $8.2 \%$ of adolescents who had control over internet use. Items of snacking pattern were significantly different among adolescents based on levels of internet addiction $(\mathrm{p}<0.001 * *)$.

Figure (2): Represent the levels of diet quality of the studied adolescents. It revealed from the figure that three-quarters $(75 \%)$ of studied adolescents had bad quality of their diet, while one-fourth $(25 \%)$ of them had good quality of diet with the mean score of diet quality was $28.14 \pm 4.21$.

Table (5): Shows the relationship between internet addiction test and diet quality of the studied adolescents. Regarding the four food groups that should be consumed, it was found that more of studied adolescents who had control over internet use were consuming the four food groups that should be consumed than studied adolescents who had occasional to frequent problem and significant problem due to internet use with a mean 13.12 \pm 2.41 , $9.09 \pm 3.71$, and $8.84 \pm 1.59$ respectively.

It also noticed that the mean of consuming varied and regular diet of studied adolescents who had control over internet use was more than their counterparts (the mean was 6.8 \pm 1.3 ).

On the opposite side, studied adolescents who had occasional to frequent problem and significant problem due to internet use were consuming the four food groups of which limited amounts should be consumed with a mean $14.27 \pm 2.87$ and $17.16 \pm 1.41$ respectively more than studied adolescents who had control over internet use. Statistical significant difference was found between diet quality and internet addiction $(\mathrm{p}=0.001 * *)$.

\section{Discussion}

Technology plays an important role in our daily life, but sometimes this role can be harmful to our health if it exceeds the limits. Adolescents are using the internet heavily and this may impact their dietary habits preferences. These risk-behaviors are the main helping factors which can lead to illness between adolescents and young individuals. The association of poor nutritional habits with internet addiction is relatively unexplored (Abdal-Qader et al., 2015). Concerning the levels of internet addiction, the present study found that almost one-quarter of studied adolescents had a significant problem due to internet use and more than one-third of them had a frequent problem from internet use as shown in figure (1). This was in the same line with a study of Liberatore et al., (2011).

These results might be due to many factors as the changes in the routine of our daily life and the preoccupation of parents with their jobs and positions more than before, lack of social communication and dialogue, the amount of time spent with their children was limited than before which lead the parents to compensate their children by providing the latest technology available such as iPad, iPhone, mobile, tablets, laptops and others. These factors could make teenagers busy with everything that is new in this technology especially with social communication and friendship where they could find friends and peers to communicate with. Furthermore, they begin to indulge in online gaming.

The difference was statistically significant between internet addiction and change in dietary habits as shown in table (2) This result was in agreement with Abdal-Qader et al., (2015) who conducted a study about "nutritional habits among internet users in a private Malaysian Medical School" found a significant correlation between internet addiction and poor nutritional habits in adolescents. In the present study, the researcher demonstrated that adolescent students with significant problem from internet use eat big meals, decrease appetite, skip meals, and snack more than their counterparts who had frequent problems due to internet use or had control over internet use.

The current study revealed that the dietary habits of students who had significant problem from internet use had been changed to have big meal sizes and there was statistical significant difference between internet addiction and changing in meal size. This was in contrary to the result of Kim et al., (2010) who found that high-risk internet users eat smaller meals than their potential-risk and normal-risk internet user counterparts.

This could be due to skipping breakfast so they feel that they were very hungry and needed to eat large meal to feel full. This result was also explained by the studied adolescents, who expressed that they eat one big meal rather than three small meals because they have no time to eat three meals daily.

The existing study also found that the majority of students who had significant problem due to internet use had a worse appetite than adolescents who had control over internet use and occasional to frequent problem due to internet usage. This was agreed with Kim et al., (2010) \& Durkee (2016) who illustrated that poor appetite and physical inactivity were shown to be significantly associated with problematic internet use. This may be because internet addicts prefer to stay online rather than eating.

Regarding the changes in eating speed, there was statistical significant difference between levels of internet addiction and changes in eating speed. More than fifty percent of adolescents who had significant problem due to internet use had fast eating speed. In 
addition; about two-thirds of adolescents who were having occasional to frequent problem due to internet usage also answered that their eating speed was irregular. These results were concurrent with Kim et al., (2010) who showed that more of high-risk internet users had irregular eating speeds than no risk internet users. This may be attributed to the fact that the preoccupation of adolescents with returning to online activity during eating time made them to hurry to finish the mealtime and return to internet.

The findings of this study indicated that there was statistical significant difference between level of internet addiction and skipping meal of the studied adolescents. Adolescents who had significant problem due to internet use had a high prevalence of skipping breakfast and dinner meal as shown in table (3). As well there was statistical significant difference between level of internet addiction and snaking pattern of the studied adolescents as cleared in table (4). The majority of adolescents who were having significant problem due to internet use snacked frequently, often snacking more than three times per day.

These results were in the same line with Thakur et al., (2018), El Sayed et al., (2015), Chathoth et al., (2014), Musaiger \& Kalam (2014) \& AlMuammar et al., (2014) they reported higher incidence of meal skipping, snacking and impairment of hobbies in internet addicts. Also, found that all of the high school students ate daily snakes and the majority of adolescent students consumed snakes between breakfast and lunch as well as between lunch and dinner. They mentioned that changes in adolescents' lifestyle such as lack of time for eating, influence of the internet with the habit of eating out home were the main reason for snacking.

The higher frequency of skipping breakfast might be due to staying up late at night and may get up too late to have breakfast. Also near half of the addict students in our study reported that the reasons for meal skipping were overslept. While the higher prevalence of skipping dinner; might be due to more snacking.

Results of the current study confirmed that the diet quality of students with a significant problem from internet use is poorer than that of other counterparts. This was in the same line with Kim et al. (2010) who found that high-risk internet users had an "inappropriate" diet quality. The statistical significant difference was found between diet quality and internet addiction. This was continuous with $\mathbf{L i}$ et al., (2014) who found that there was a relationship between problematic internet use and a poor diet quality had been established resulting in weight problems, such as obesity.
The current study found that there was a statistical significant difference between internet addiction and the four food groups that should be consumed in limited amounts such as fried and fatty food, salts, drinking soda as shown in table (5).

Students who had occasional to frequent problem and significant problem due to internet use were consuming too little of the recommended food groups such as milk and dairy products, meat and fish, and fruits and vegetables. Moreover, they consume more fatty food, fried food, salt, cake, and drink soda between meals compared with students who had control over internet use. Decrease intake of fruits and vegetables in problematic internet users mean low intake of vitamins, minerals, and fiber in these adolescents. As vitamins and minerals play an important role in energy production, maintenance of bone health, adequate immune function, and protection against stress (Davis et al., 2009).

These results agreed with Strasburger (2010) who conducted a study about "health effects of media on children and adolescents " and found that long hours of online browsing and gaming not only cause sedentary lifestyle but also promote unhealthy eating patterns and promote food which are low in nutritive values and high in fat and calories. In addition to the study by Abd al Qader et al., (2015) who found that there was a significant relationship between carbonated drink cans and internet usage and more than half of the adolescents eat outside the house daily. About two-thirds of them eat one serving of fruits per week, while almost one-third eat 2-3 servings of vegetables per week. Also, the present study demonstrated that a significant relation was found between internet addiction and eating varied and regular meals. This may be due to adolescents who spend more time online so they ignore regular meals and eat whatever is available.

The current study found that more than two-thirds of studied adolescents who had a significant problem due to internet use were males and the difference was statistically significant between internet addiction levels and sex as shown in table (1) These results were consistent with the study of Shahnaz \& Karim (2014), Kim et al., (2010) \& Hsu \& Chuang (2008) who found that more boys were high-risk internet users than girls. They also found that the male-tofemale ratio for IA was almost four to one.

This result was disagreed with Hashemian et al., (2014) and Ghamari et al., (2011) who found that the prevalence and risk of internet addiction were higher in female students in comparison with male students. Also, Lam et al., (2009) who conducted a study about "factors associated with internet addiction among adolescents" found no gender differences in relation to internet addiction (IA). 
This gender difference could be explained that our society's culture give the boys more freedom as regard social activity and their free time. Also, these social activities were less controlled by their parents. However, the parents became more assertive with girls. Likewise, boys were more advanced in information and communication technologies and become encouraged to engage in addictive activities. But, the girls were more engaged with their mothers in housework and get less free time to be involved in addictive activities.

\section{Conclusion}

Based on the current study findings it was concluded that there was a statistically significant difference between levels of internet addiction and dietary behavior of studied adolescents. Adolescent students with significant problem from internet use eat big meals, lost their appetite, skipped meals, and snacked more than their counterparts who had control over internet use. Furthermore, the diet quality of students with significant problem from internet use was poorer than that of other counterparts.

\section{Recommendations:}

1. Raising adolescents' awareness about adverse effects of internet addiction on their development such as poor dietary behavior; through mass media and health education program in the schools and family-centered care.

2. Health care professionals especially the pediatric nurse should educate the adolescent students what a balanced diet to remain healthy and maintain growth.

3. Secondary schools should include in their educational program, symposium, and seminars about adolescents' health, nutrition, and safe use of internet.

\section{References}

1. Abdal-Qader M., Ghazi H., Hasan T., and Mohammed M., (2015): Nutritional habits among internet users in a private Malaysian medical school. Pakistan Journal of Nutrition; 14 (7): 409-411.

2. Abd El-Tawb (1998): Socio economic scale, Faculty of Education, Assiut University

3. Al-Muammar M., El-Shafie M., \& Feroze S., (2014): Association between dietary habits and body mass index of adolescent females in intermediate schools in Riyadh, Saudi Arabia.; 20 (1):39-45.

4. Center for Disease Control \& Prevention. (2010): Beverage consumption among high school students--United States. Available at http://www. cdc.gov/ mmwr/ pdf/wk/mm6023.pdf.retrived at 20-3-2018

5. Chathoth V., Kodavanji B., Kumar N., Anupama N., Kini R., \& Pai S., (2014): Impact of internet use on lifestyle in undergraduate medical students: International Journal of Biomedical Research ;12(5): 551-555.

6. Davis E., Cullen K., Watson K., Konarik M., \& Radcliffe J., (2009): Fresh fruit and vegetable program improves high school students consumption of fresh produce. J Am Diet Assoc; 109(7):1227-31 Available at https://www.ncbi.nlm.nih.gov /pubmed/19559140. Retrived at 22-11-2017

7. Durkee T., Carli V., \& Floderus B., (2016): Pathological internet use and risk-behaviors among European adolescents. International Journal of Environmental Research and Public Health. Mar; 13(3): 294. Available at https://doi.org/10.3390 /ijerph13030294Retrived at $13-8-2018$

8. Eccles J., (2011): The development of children ages 6 to 14. The future of children. 9(2) 30-45 available at https://pdfs.Semantics cholar.org/.../ 31 eed233d80c076305010522f93Retrived at 1611-2017

9. El Sayed H., El-Shafei M., \& Toprak L., (2015): Influence of dietary habits of university students on body mass index (BMI) (a comparative study among Egypt and Saudi Arabia and turkey). Firat University Journal of Social Science; 25(2): 315-328.

10. Ghamari F., Mohammadbeigi A., Mohammadsalehi N., \& Hashiani A., (2011): Internet addiction and modeling its risk factors in medical students, Iran. Indian J Psychol Med; 33(2):158-62

11. Gür K., Yurt S., Bulduk S., \& Atagöz S., (2015): Internet addiction and physical and psychosocial behavior problems among rural secondary school students. Nursing health science. Sep ;17(3):331-8

12. Hashemian A., Direkvand A., Delpisheh A., Kolivandz, \& Abasi M., (2014): Prevalence of internet addiction in iranian high school students; a cross-sectional study, Journal of Basic Research in Medical Science 1(3):39-44.

13. Hsu Y. \& Chuang O. (2008): Are internet cafés gendered spaces? Cyberpsychology and Behavior; 11(2): 224-226.

14. Internet Users Statistics for Africa in millions. (2018): available at .https://www.internetworldstats.com/africa.htm.R etrived at 14-3-2018

15. Internet Users Statistics for Africa. (2017): in millions: available at. https://www.statista.com > 
Internet > Demographics \& Use. retrived at 16-92017

16. Internet world status \& Egypt internet usage \& telecommunications report (2012): Available at http://www. internetworldstats.com/af/eg.htm. Accessed 2012. ISSN: 2005-4246 IJUNESST Copyright (C) 2016.Retrived at 16-9- 2017

17. Kawabe K., Horiuchi F., Ochi M., Oka Y., \& Ueno S., (2016): Internet addiction: Prevalence and relation with mental states in adolescents: Internet addiction in adolescents. Psychiatry and Clinical Neurosciences; 70 (9): 405-412. doi. /10.1111/pcn.124022013.803111

18. Kim W., Cho M., \& Lee H., (2003): Development and validation of mini dietary assessment index for Koreans. The Korean Journal of Nutrition 2003; 36:83-92.

19. Kim Y., Park Y., Kim S., Jung In., Lim S., \& Kim H., (2010): The effects of internet addiction on the lifestyle and dietary behavior of Korean adolescents. Nutrition Research and Practice; 4(1): 51-57 Available at https://www.researchgate.net/.../41670032. retrived at: 19/9/2017.

20. Lam L., Peng Z., Mai J., \& Jing J., (2009): Factors associated with internet addiction among adolescents. Cyber psycho Behav; 12 (2):1- 5.

21. Li M., Deng Y., Ren Y., Guo S., \& He X., (2014): Obesity status of middle school students in Xiangtan and its relationship with internet addiction; 22(2): 482-487. pmid:23929670

22. Liberatore K., Rosario K., Colon-De L., \& Martínez K., (2011): Prevalence of internet addiction in Latino adolescents with psychiatric diagnosis. Cyberpsychol BehavSoc Net.; 14(6):399-402.

23. Malak M., Khalifeh A., \& Shuhaiber A., (2017): Prevalence of internet addiction and associated risk factors in Jordanian school students. Computers in Human Behavior, 70(C) 556-563. doi: 10.1016/j.chb.2017.01.011

24. Musaiger A., \& Kalam F., (2014): Dietary habits and lifestyle among adolescents in Damascus, Syria. Annals of Agricultural and Environmental Medicine; 21(2): 416-419.

25. Musaiger A., Al-Mannai M., \& Tayyem R., (2013): Risk of disordered eating attitudes among adolescents in seven Arab countries by gender and obesity: a cross-cultural study. Appetite 60 (1):162-167. doi:10.1016/j.appet.2012.10.012

26. Odac H., \& Kalkan M., (2010): Problematic internet use, loneliness and dating anxiety among young adult university students. Comput Educ; 55(3):

1091-1097.
27. Shahnaz I., \& Karim A., (2014): The impact of internet addiction on life satisfaction and life engagement in young adults. Universal Journal of Psychology; 2(9) : 273 - 284.

28. Statistics of internet users worldwidein millions. (2015): Available at http://www.statista.com/statistics/273018/number -of-internet-users-worldwide .Accessed at 14 December 2015retrived at 22-9-2017.

29. Strasburger V., Jordan A., \& Donnerstein E., (2010): Health effects of media on children and adolescents. Pediatrics; 125(4): 756-776.

30. Thakur A., Peepre K., Vaswani A., Gupta K., Verma A., Singh D., \& Kasar P., (2018): Internet addiction, behavioral aspects, and health related problems associated with it: International Journal of Research in Medical Sciences. Jan; 6(1):253-258 available at www.msjonline.org

31. The Surgeon General's Call To Action To Prevent and Decrease Overweight and Obesity. (2012): available at http: // www. Surgeongeneral.gov/topics/obesity/ calltoaction/fact_adolescents.html. Retrived at 174-2018

32. United Nations, (2011): Internet as a catalyst for change. Access, development, freedoms and innovation. The sixth Internet Governance Forum, Nairobi, Kenya (accessed 17 August 2012) Available from URL:http://www.intgovforum.org/cms/2012 /Book/IGF 2011_Book_Final\%20copy.pdf.

33. Vondrácková P., \& Gabrhelík R., (2016): Prevention of internet addiction: A systematic review, Journal of Behavioral Addictions; 5(4):568-579

34. Young K., (2004): Parent-child internet addiction test [Online]. Available :http:Internetaddiction.com/resources/parents_test .htm. rsing \& Health Sciences, 2015; 17(3):331338. 1

35. Young K., (1998a): Internet addiction: The emergence of a new clinical disorder. CyberPsychology and Behavior, 1(3), 237-244.

36. Young K., (1998b): Caught in the net: How to recognize the signs of internetaddiction- and a winning strategy for recovery. John Wiley, New York. 